Article

\title{
Protecting Youths' Wellbeing Online: Studying the Associations between Opportunities, Risks, and Resilience
}

\author{
Joyce Vissenberg * and Leen d'Haenens \\ Institute for Media Studies, KU Leuven, 3000 Leuven, Belgium; E-Mails: joyce.vissenberg@kuleuven.be (J.V.), \\ leen.dhaenens@kuleuven.be (L.d’H.) \\ * Corresponding author
}

Submitted: 10 January 2019 | Accepted: 29 March 2020 | Published: 19 May 2020

\begin{abstract}
As youths engage in different activities on the Internet, it is inevitable that they are exposed to risky online contents that might bother or upset them. Previous research has shown that online resilience, or the ability to effectively cope with online risks and to deal with their negative consequences, protects youths against these feelings of harm that sometimes emerge after a risk experience. However, knowledge about the role of resilience in protecting youths' overall wellbeing seems rather limited. The current study analyzes new EU Kids Online data using structural equation modeling to fill this gap. The findings corroborate earlier findings that the more opportunities youths take up online, the more they are exposed to risky content. These risk encounters are negatively associated with wellbeing. Online resilience moderates this association and protects youths' overall wellbeing from being harmed by online risk exposure. Implications for further research and practice are discussed.
\end{abstract}

\section{Keywords}

EU Kids Online; online opportunities; online resilience; online risks; wellbeing; youth

\section{Issue}

This article is part of the issue "Youth Digital Participation: Opportunities, Challenges, Contexts, and What's at Stake" edited by Neta Kligler-Vilenchik (Hebrew University of Jerusalem, Israel) and Ioana Literat (Teachers College, Columbia University, USA).

(C) 2020 by the authors; licensee Cogitatio (Lisbon, Portugal). This article is licensed under a Creative Commons Attribution 4.0 International License (CC BY).

\section{Introduction}

Digital media have become ubiquitous in youths' everyday lives. Their smartphones allow them to communicate with friends and family, to stay up to date with current events, and to play games against opponents from all over the world. The activities that children and youths engage in online are often termed 'opportunities' due to their substantial value for their psychosocial development and overall wellbeing (Livingstone, Haddon, Görzig, \& Ólafsson, 2011; Valkenburg \& Peter, 2011).

However, as youths engage in a broader range of online opportunities, it becomes inevitable that they encounter some risks along the way (Livingstone \& Helsper, 2010). Three types of online risks that children and youths can be exposed to have been identified
(Hasebrink, Livingstone, \& Haddon, 2009). The first type consists of content risks, such as when youths are exposed to violent or sexual images. The second type refers to contact risks, such as when they engage in sexting. The third type relates to conduct risks, with a clear perpetrator, for example in cyberbullying. The current study will specifically focus on content risks, as Flemish youths are generally more exposed to potentially harmful online contents than the European average (Smahel et al., 2020). They are mainly exposed to hate speech (21\%), drug-related contents (16\%), and violent contents (16\%; Vissenberg \& d'Haenens, 2020).

Parents, experts, and policy makers have raised concerns about the potentially harmful outcomes of exposure to these risks (Lwin, Li, \& Ang, 2012). In this study, we conceptualize feelings of harm as feeling both- 
ered, upset, or uncomfortable after an online experience or wishing that they had not seen the risky content (Livingstone et al., 2011). However, research has shown that not all youths feel harmed after encountering a negative experience online (Livingstone et al., 2011). Online resilience is a key protective factor from these feelings of harm: Resilient youths employ effective coping strategies to prevent negative online experiences or to deal with the consequences of them, and are hence more protected than less resilient children to feelings of harm after a risky online experience (Vandoninck, d'Haenens, \& Roe, 2013).

Previous research has found evidence for a clear association between online opportunities and online risks and their respectively positive and negative influence on wellbeing (Livingstone, Mascheroni, \& Staksrud, 2015). However, knowledge about the role of resilience in protecting youths' wellbeing from potential harmful outcomes from online content risks experiences seems limited, as previous studies have mainly focused on preventing the feelings of harm that take place immediately after a negative online experience. The current study aims to fill this important gap. Early research on the effects of media exposure on children and youths often adopted a protectionist perspective, in which these young audiences were seen as passive, impressionable, and vulnerable receivers of different potentially harmful media contents (Kellner \& Share, 2007). Scholars that take this protectionist stance generally assume technological determinism and perceive children and youths as "the product of interacting external forces including media influences" (Livingstone, 2016) without having any control over their developmental trajectories themselves. Furthermore, media are generally seen as the cause of harmful effects. This perception of media has fueled anxieties and moral panics that these contents have effects on young audience's attitudes, beliefs, and behavior (Fry, 2015; Livingstone, 2016), which is seen in the research literature on the effects of violent and pornographic content on children's and youths' perceptions of the world (Livingstone, Mascheroni, \& Staksrud, 2018). Researchers that position themselves within this protectionist approach to media mainly propose restrictions to media exposure as a means of preventing the harmful effects of media on younger audiences.

In recent years, however, scholars have increasingly criticized the protectionist approach for "its anti-media bias, its over-simplification of the relationships that audiences have with media and for taking away the potential for empowerment" (Kellner \& Share, 2007). As a result, much research on children, youths, and media today has shifted towards an empowerment approach. The current study, and the broader EU Kids Online project, also places itself within this framework. Scholars within this tradition perceive youthful audiences as active agents who dynamically engage with media to shape their lives. Media are considered to be an essential means to their development (Livingstone, 2016). As these media, and especially the Internet, take an increasingly prominent position in different areas of children's and youths' lives, researchers are focusing on how their Internet use can be optimized to maximize the different opportunities the Internet has to offer and to minimize the risks that come with it (Livingstone et al., 2017). The focus of research on children, youths, and media has hence shifted from Internet safety to a better Internet for children and youths in the digital age (Fry, 2015; O'Neill, Staksrud, \& Mclaughlin, 2013). Researchers within the EU Kids Online network have focused on the ways in which children and youths use the Internet, the meanings they give to their Internet use, the opportunities they take up and the risks they encounter, and their digital competences to unravel the ways in which the Internet can benefit different aspects of children's and youths' lives the most (Livingstone et al., 2018).

\section{Literature Review}

\subsection{Online Opportunities and Exposure to Risky Content}

Young people's Internet use has been extensively studied and classified. In general, researchers distinguish between different types of online activities such as communication, information seeking, and entertainment, among others (Ito et al., 2010). Studies have revealed that communication-related activities in particular have become popular among youths, especially since the rise of social networking sites (Apestaartjaren, 2018; Vandoninck, d'Haenens, \& Ichau, 2014). All online activities which are most likely to produce beneficial outcomes for youths, such as for their psychosocial development or their wellbeing, are termed 'opportunities' (Livingstone et al., 2011). Furthermore, building on Giddens's (1991) notion that identities are shaped through social interactions, Livingstone (2008) argues that the Internet provides youths with the affordances to experiment with different aspects of adolescence. These processes, however, are "understood in terms of a balance between opportunity and risk" (Giddens, 1991, p. 78). The current study includes seven types of opportunities that youths take up online and that allow them to shape their identities in this crucial stage of life: communication, help and information seeking, gaming, participation, creation and sharing of user-generated content, entertainment, and online shopping.

However, these activities do not always prove beneficial to all youths and might even constitute risks, which are online activities that might produce harmful outcomes, for some (Livingstone et al., 2011). More than a third of Flemish youths (38\%) indicate having encountered a negative experience on the Internet in the past year, $26 \%$ did so at least once a month (Vissenberg \& d'Haenens, 2020). Important to note is that these activities are often labeled as risks by parents or other adults, while they are not necessarily perceived as negative experiences by the child itself (Livingstone et al., 
2015). This article studies youths' exposure to risky online content from this adult perspective, as we predefined different types of risky content to which youths can be exposed on the Internet in our questionnaire, such as contents related to self-harm, eating disorders, or drug use. Recent studies have revealed that youths regularly encounter potentially harmful content on the Internet and that exposure to different types of these contents is interrelated: If youths report being exposed more to one type of content, they are also more likely to encounter other types of risky contents on the Internet (Smahel et al., 2020). Flemish youths report being exposed the most to contents concerning hate speech (21\%), drug use (16\%), and violence (16\%; Vissenberg \& d'Haenens, 2020).

Several characteristics predict youths' exposure to online risks. Concerning age, younger children are exposed to these types of content to a far lesser extent than adolescents (Livingstone et al., 2011). Especially from the age of 13 , which is the age that Belgian youths start secondary school, exposure to potentially harmful content increases (Vandoninck et al., 2014). This can be explained by increased time spent online and the risk-taking behavior that characterizes adolescence (Görzig, 2016; van Nieuwenhuijzen et al., 2009). Gender seems to play a role in the exposure to some types of content. For example, girls, especially between the ages of 14 and 16, are more likely than boys to see pro-anorexic or bulimic contents (Livingstone et al., 2011). Other than demographic characteristics, youths' online risk experiences are predicted by the extent to which they take up online opportunities, even when controlling for the time they spend online (Livingstone \& Helsper, 2010). It is indeed inevitable that youths, when they engage in a broader range of online activities, are exposed to some risky content along the way. Based on this finding, we propose the following hypothesis:

$\mathrm{H} 1$ : There is a positive association between online opportunities and online content risks.

Researchers agree that the distinction between online opportunities and online risks lies in their effects on the user's wellbeing. While 'opportunities' generally produce beneficial outcomes, activities that are termed risks might have harmful consequences (Livingstone et al., 2011), preventing youths to benefit fully from their Internet use (El Asam \& Katz, 2018). Research has found support for positive outcomes of online opportunities for youths' wellbeing (e.g., communication opportunities and social wellbeing) and negative effects of exposure to risky online content on their wellbeing. For instance, youths who report being exposed more to online hate messages report lower levels of wellbeing than youths who are less exposed (Keipi, Oksanen, Hawdon, Näsi, \& Räsänen, 2017; Keipi, Räsänen, Oksanen, Hawdon, \& Näsi, 2018). Similarly, a diary study by McHugh, Wisniewski, Rosson, and Carroll (2018) found that expo- sure to explicit online content evokes symptoms of posttraumatic stress disorder in youths. Based on these findings, we propose the following hypotheses:

$\mathrm{H} 2$ : There is a positive association between online opportunities and youths' wellbeing.

H3: There is a negative association between online content risk exposure and youths' wellbeing.

\subsection{Online Resilience}

While concerns have been raised about the potentially harmful outcomes of exposure to risky online content, it is necessary to mention that not all youths that have a negative experience online feel bothered, harmed, or upset afterwards (Livingstone et al., 2011). For example, only slightly more than a third of European youths (38\%) who had been exposed to sexual images on the Internet and only $8 \%$ of youths who had an offline meeting with someone they first met online report feeling upset afterwards (Smahel et al., 2020).

Some youths indeed seem to be more resilient to harm after online risk experiences than others (d'Haenens, Vandoninck, \& Donoso, 2013; Staksrud \& Livingstone, 2009). Resilience is a central concept in different developmental and socialization theories in the field of psychology and is generally defined as the "positive patterns of adaptation in the context of risk or adversity" (Masten \& Gewirtz, 2006). Already from a young age, children and youths develop different skills and characteristics that aid them in protecting themselves from and effectively dealing with the negative situations that they might come across. These skills and characteristics include self-confidence (Ito et al., 2008), autonomy (Baumrind, 1991), identity building and self-expression (Strasburger, Wilson, \& Jordan, 2014), and social skills (Pabian \& Vandebosch, 2016). Resilience is hence understood as a dynamic process of trial and error rather than a fixed trait, in which people gradually learn to deal with or adapt to difficult or stressful situations they encounter. For this resilience to develop, exposure to risky situations is crucial, as this is when people truly learn to deal with the negative situation that they are in at that moment (Coleman \& Hagell, 2007; Vandoninck et al., 2013).

In the context of online risks, resilient youths are "able to deal with a negative experience online": i.e., they do not remain passive but display problem-solving coping strategies in order to protect themselves from future harm (Vandoninck, d'Haenens, et al., 2013). Online resilience serves as an important protective factor against feelings of harm after a negative online experience (Hinduja \& Patchin, 2017). Youths that are more resilient are less likely to feel harm after an online risk experience than those who are less resilient. The majority of young people seems to be quite resilient to harm from risky online experiences (El Asam \& Katz, 2018; Livingstone et al., 2011). 
The coping strategies that youths employ to deal with a negative online situation are a good indicator of their level of resilience, as resilient youths cope in proactive ways with the aim of preventing or reducing feelings of harm while less resilient youths often resort to rather passive strategies (Vandoninck, d'Haenens, et al., 2013). Coping is defined as "the efforts to adapt to stress or other disturbances by a stressor or adversity in order to protect oneself from the psychological harm of risky experiences" (Masten \& Gewirtz, 2006). Online coping can be described as "Internet-specific problem-solving strategies children adopt after a negative experience online" (Vandoninck et al., 2013). Some youths cope more effectively with online adversities than others and are hence more resilient to harm from online risks (Livingstone et al., 2011; Smahel \& Wright, 2014; Staksrud \& Livingstone, 2009; Vandoninck \& d'Haenens, 2015; Vandoninck et al., 2013). Research has shown that youths that have more difficulties coping with offline risks also have more difficulties coping with online risks (Vandoninck, d'Haenens, \& Segers, 2012).

Youths generally employ one or more of three types of coping strategies after online risk experiences (Livingstone et al., 2011). The first type is fatalistic or passive coping, where the child does not take any initiative to actively deal with the cause of the problem. Youths that cope in a passive manner will for example neglect the problem or hope that it will go away by itself. The second type is communicative coping, where the child seeks social support and talks to someone trustworthy, such as parents or peers, about the problem to reduce feelings of harm. The third type of coping is proactive or problem-solving coping, whereby the child will act when faced with problems to reduce or eliminate harmful outcomes in the future, such as blocking the sender of a potentially harmful message. Resilient youths use proactive or communicative coping strategies to deal with risky online experience to prevent feelings of harm (d'Haenens et al., 2013; Vandoninck et al., 2013). Both problem-solving and communicative strategies are favorable coping strategies because they are aimed at actively preventing or tackling the problem. Less resilient children use passive or avoidant coping strategies and often do not succeed at preventing or eliminating negative emotions that resulted from the online risk experience (Vandoninck et al., 2013).

Previous research has laid bare the associations between exposure to risky content and the harmful outcomes for youth wellbeing. Studies that included resilience, however, mostly focused on its role in reducing or preventing feelings of harm that take place after the risky experience. While some studies have found associations between the use of specific coping strategies and overall wellbeing (Lazarus, 2006; Machmutow, Perren, Sticca, \& Alsaker, 2012; Seiffge-Krenke \& Klessinger, 2000), knowledge about the protective role of resilience between exposure to risky online content and overall wellbeing seems rather limited. Therefore, we propose the following research question:

RQ1: What role does online resilience play in the association between online content risk experiences and wellbeing?

\section{Methods}

\subsection{Data and Sample}

This study uses survey data from the 2018 data collection wave of EU Kids Online, a European research project that aims to enhance the knowledge about European children's and youths' Internet use, risks, and online safety. The research population for this study includes youths between 13 and 20 years old that are enrolled in secondary schools in Flanders - the Dutch-speaking part of Belgium. The respondents were recruited using two-stage sampling. In a first stage, Flemish secondary schools were contacted with a request to participate in the study. Schools that agreed moved on to the second stage, proposing classes of pupils that would take the survey. To gather a sample that was representative to the Flemish adolescent population, we aimed at an even distribution of age, gender, and education option (General Secondary Education, Vocational Secondary Education, Art Secondary Education, and Technical Secondary Education). Data were collected between March and May 2018 and between October and November 2018.

The researchers visited the classes that agreed to participate in the study to provide a short explanation of the purpose of the study and to answer any questions that the pupils might have while taking the survey. The online survey was set up in Qualtrics and was taken on computers in computer classes at the school. It took around 50 minutes to complete the survey. In total, 1436 Flemish youths completed the survey. The sample consists of 668 boys (46.7\%) and 704 girls (49.2\%) with a mean age of 16.08 (SD = 1.97).

\subsection{Measures}

Table 1 (in Supplementary File) presents the measurement information and means of items for the latent variables online opportunities, online content risks, and online resilience.

\subsubsection{Online Opportunities}

The respondents were provided with a list of 30 opportunities that users can take up online. They were asked to indicate how often they had engaged in each activity in the past month on a 6-point Likert scale with answer options ranging from 'never' (1) to 'almost always' (6). Parallel analysis and principal components analysis with direct oblimin rotation show that seven types of opportunities should be distinguished: communication, help and 
information seeking, gaming, participation, creation and sharing of user-generated content, entertainment, and online shopping. Confirmatory factor analysis (CFA) reveals that these seven factors all load on the higher-order latent variable 'opportunities.' The CFA model for opportunities was bootstrapped using the Bollen-Stine method (Bollen \& Stine, 1992) with 10,000 draws to correct for potential biases due to the non-normal distribution of the data. The results reveal that this model had a good fit $\left(\chi^{2}=307, \mathrm{df}=223, \mathrm{p}<.05, \mathrm{CFI}=.99\right.$, RMSEA $=.02$, SRMR $=.02)$. The latent variable 'opportunities' has excellent internal consistency (Cronbach's $\alpha=.93$ ).

\subsubsection{Online Content Risks}

The respondents were asked to indicate how often they had come across six types of potentially harmful content in the past year on a 5-point Likert scale with answer options ranging from 'never' (1) to 'always or almost always' (5). These six types of content were sexual content, self-harm related content, suicide-related content, eating disorder-related content, hate speech, drug-related content, and violent content. Sexual contents were not included in this list, but were measured in a separate question and later added into the measurement model for online content risks. CFA reveals that these seven types of risk all load on one latent variable 'content risk exposure.' Because the data was not normally distributed, which might cause potential biases, the model was bootstrapped with 10,000 draws using the Bollen-Stine method (Bollen \& Stine, 1992). This model showed a good fit to the data $\left(\chi^{2}=23.36, \mathrm{df}=14\right.$, $\mathrm{p}>.05, \mathrm{CFI}=.99, \mathrm{RMSEA}=.02, \mathrm{SRMR}=.01)$ and excellent internal reliability (Cronbach's $\alpha=.92$ ).

\subsubsection{Online Resilience}

The use of coping strategies aimed at preventing or actively reducing feelings of harm was used as a proxy for online resilience. The survey included two questions to identify youths' use of three types of coping strategies: communicative coping, proactive coping, and passive coping. In the first question, the respondents were asked about their communicative coping strategies and had to indicate the people they talk to after an online risk experience, such as their parents or friends $(0=$ no, $1=$ yes). In the second question, the respondents' proactive and passive strategies were surveyed. They were asked to indicate which actions they had taken after an online risk experience ( $0=$ no, $1=$ yes), such as neglecting the problem or blocking the sender. As previous studies show that resilient youths employ communicative and/or proactive strategies (Vandoninck et al., 2013), only the items concerning communicative and active strategies, and not passive strategies, were combined into the latent variable 'online resilience.' The CFA model was bootstrapped with 10,000 draws using the Bollen-Stine method (Bollen \& Stine, 1992) to correct for potential biases due to non-normality in the data. The model has a good fit to the data $\left(\chi^{2}=242.03, \mathrm{df}=63\right.$, $\mathrm{p}>.05, \mathrm{CFI}=.95, \mathrm{RMSEA}=.04, \mathrm{SRMR}=.03)$ and shows good internal consistency (Cronbach's $\alpha=.77$ ).

\subsubsection{Wellbeing}

In the EU Kids Online surveys, wellbeing is measured using the following question (Livingstone et al., 2011): "Imagine that 10 is the best life for you and 0 is the worst life for you. Where on the scale do you feel you stand at this moment?" Answer options ranged from 10 to 0 $(\mathrm{M}=7.09, \mathrm{SD}=1.71)$.

\subsubsection{Control Variables}

This study controls for age, gender, and the time spent online, as previous research has shown that these variables are associated with online opportunities and risk experiences (Livingstone \& Helsper, 2010). To measure the time spent online, the respondents had to indicate how much time they spent online during the week and during the weekend, with answer options formulated as 'Never or little time,' 'Approximately 1 hour,' 'Approximately 2 hours,' etc.

\subsection{Analysis}

We performed Mardia's skewness and kurtosis tests to investigate the multivariate normality of the data. As the $p$-value for both the skewness and the kurtosis tests was 0 , the null hypothesis of Mardia's test that the observations are multivariate normally distributed is rejected, indicating that the data in this study are not normally distributed.

We used structural equation modeling (SEM) to test our hypotheses and to answer our research question, which we performed using the lavaan package in $\mathrm{R}$ (Rosseel, 2012). Through a combination of factor analysis and multiple regression analyses, SEM allows for the definition of multiple latent variables and the estimation of the relationships between these variables in one model. Therefore, SEM is the preferred technique when analyzing associations between multiple latent variables (Kline, 2011). Despite the fact that the maximum likelihood estimator is relatively robust to non-normally distributed data, $p$-values and fit measures might be biased (Bandalos, 2014). Moreover, the bias that results from this non-normality might be inflated due to the presence of missing data. 727 cases in the dataset did not contain any missing values and were included in the model. A total of 709 missing cases seems high, but Kline (2011) suggests that bootstrapping can be applied to deal with these issues. The Bollen-Stine bootstrap method (Bollen \& Stine, 1992) proves particularly useful in solving issues related to non-normally distributed datasets containing missing data (Enders, 2002). Therefore, the fit measures of the model were bootstrapped using the Bollen-Stine 


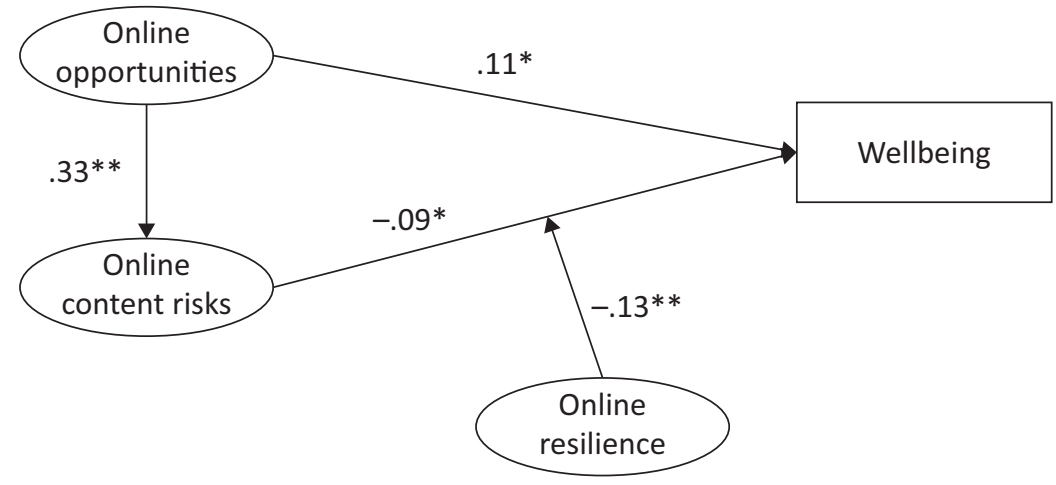

Figure 1. Path model for online opportunities, online content risks, online resilience, and wellbeing. Notes: For clarity, the measurement model is not pictured and the control variables are not included in this figure. Results that include the control variables and unstandardized coefficients can be found in Table 1 . Note: ${ }^{*} p<.05,{ }^{* *} p<.01$.

method (Bollen \& Stine, 1992) and the $95 \%$ and $99 \%$ confidence intervals of the $p$-values were ordinarily bootstrapped. Both bootstraps contained 10,000 draws.

\section{Results}

The path model in Figure 1 was constructed to test the hypotheses and to answer the research question. As this model provided answers to all hypotheses and the research question and it has a good fit to the data $\left(\chi^{2}=1300.80, \mathrm{df}=1013, \mathrm{p}<.01, \mathrm{CFI}=.97, \mathrm{RMSEA}=.02\right.$, SRMR $=.03$ ), it was not modified further. The full model, including control variables, is presented in Table 1.

$\mathrm{H} 1$ expected a positive association between the opportunities youths take up and their encounters of risky content on the Internet. We found support for this hypothesis, as online opportunities seem to be a positive predictor for online content risk experiences $(\beta=.33$, $\mathrm{SE}=.14, \mathrm{p}<.01)$. Hence, while we controlled for age, gender, and the time spent online, youths who take up more opportunities on the Internet also encounter more risky content. $\mathrm{H} 2$ proposed a positive association between online opportunities and youths' wellbeing. This hypothesis was supported as well, as online opportunities significantly and positively predict youths' wellbeing $(\beta=.11, \mathrm{SE}=.17, \mathrm{p}<.05)$. Controlling for age, gender, and time spent online, youths who take up more opportunities online on average report higher levels of well- being than youths who take up a smaller range of opportunities on the Internet. H3 predicted a negative association between online content risk experiences and youths' wellbeing. This hypothesis was supported as well: online content risks significantly and negatively predicted youths' wellbeing ( $\beta=-.09, \mathrm{SE}=.05, \mathrm{p}<.05)$. Hence, while we controlled for age, gender, and time spent online, youths who encounter more risky content on the Internet report lower levels of wellbeing than youths who encounter these contents less. Important to note, however, is that the associations between both opportunities and risks and wellbeing are of nearly equal strength. Hence, their combined effects on wellbeing seem to cancel each other out.

RQ1 aimed to investigate whether online resilience protects youths' wellbeing when they are exposed to risky online content, and hence whether there is an interaction of online content risk experiences and online resilience on youths' wellbeing. The structural equation model reveals that online resilience significantly and negatively moderates the association between online content risks and wellbeing $(\beta=-.13, \mathrm{SE}=.56, \mathrm{p}<.01)$. The negative coefficient indicates that as resilience increases, the association between online content risks and wellbeing weakens. Hence, higher levels of resilience protect the wellbeing of youths after they have been exposed to potentially harmful content online.

Table 1. Unstandardized and standardized beta's and significance levels of the structural equation model for online opportunities, online content risks, online resilience, and wellbeing.

\begin{tabular}{|c|c|c|c|c|c|c|}
\hline \multirow[b]{2}{*}{ Gender } & \multicolumn{2}{|c|}{ Online opportunities } & \multicolumn{2}{|c|}{ Online risks } & \multicolumn{2}{|c|}{ Wellbeing } \\
\hline & -.06 & -.07 & -.09 & -.04 & -.41 & $-.13 * *$ \\
\hline Age & -.01 & -.04 & .05 & $.07 *$ & -.01 & -.01 \\
\hline Time online & .09 & $.36 * *$ & .06 & $.09 *$ & -.11 & $-.11 * *$ \\
\hline Online opportunities & & & .86 & $.33 * *$ & .38 & $-.11^{*}$ \\
\hline Online risks & & & & & -.13 & $-.09 *$ \\
\hline Online risks $\mathrm{x}$ online resilience & & & & & -2.456 & $-.13 * *$ \\
\hline
\end{tabular}

Notes: Unstandardized coefficients are in italics, standardized coefficients are in regular font. ${ }^{*} p<.05,{ }^{* *} p<.01$. The reference category for 'Gender' is male. 


\section{Discussion}

As youths take up more opportunities online, it is inevitable that they also have some negative experiences, such as exposure to potentially harmful content (Livingstone \& Helsper, 2010). The feelings of harm that result from these experiences can be a threat to their overall wellbeing. Online resilience, or the ability to effectively cope with online adversities, protects youths against these feelings of harm after encountering risky content (Vandoninck et al., 2013). However, knowledge about whether online resilience also protects youths' overall wellbeing is rather limited. The current study aimed to fill this gap in the literature.

This study found a positive association between the opportunities youths take up on the Internet and their levels of wellbeing. These opportunities include communication, help and information seeking, gaming, participation, creation and sharing of user-generated content, entertainment, and online shopping activities. Youths who engaged in a broader range of online activities generally reported significantly higher levels of wellbeing than youths who took up less opportunities. Furthermore, the current study is in line with earlier findings (Livingstone \& Helsper, 2010) that the more opportunities youths take up on the Internet, the more they are exposed to potentially harmful online content. The contents that were included in this study were self-harm related content, suicide-related content, eating disorderrelated content, hate speech, drug-related content, violent content, and sexual content. These content risks in turn emerge as a negative predictor of youth's wellbeing, as youths who encounter more risky content on the Internet reported lower levels of wellbeing than youths who were exposed less to these contents.

These findings might put parents, teachers, and other caretakers at a crossroads concerning the question whether or not, and to which extent, to encourage or prohibit youths to participate online. On the one hand, taking up a broad range of online opportunities seems to have direct positive value for youths' wellbeing. On the other hand, however, these opportunities inevitably entail exposure to risky online content, which in turn seems to be damaging to their wellbeing. The question about the benefits versus the harm of encouraging youths to engage in a broad range of online activities to their wellbeing arises. Weighing in on this dilemma, Livingstone et al. (2015) argue that it matters less whether youths take up opportunities on the Internet or whether they encounter risky contents online. As both have become inevitable in today's society, the authors argue that youths should protect their wellbeing by successfully balancing both the opportunities they take up and the risks they encounter on the Internet. Our findings corroborate this statement, as they show that the associations between both opportunities and content risks and wellbeing are of similar strength, which means that their effects on wellbeing cancel each other out. Hence, as long as youths actively engage in activities that they find beneficial, their wellbeing is less endangered by potential risk experiences that they might encounter along the way. Furthermore, parents, teachers, and other caretakers should be aware of the child's individual needs while being careful not to be overprotective of youths' Internet use and should instead find a balance between protecting them and allowing them to explore the online environment through various types of opportunities (Vandoninck, 2016).

Online resilience emerged as an important factor in this balance between online opportunities and exposure to potentially harmful online content. Previous studies revealed that whether youths cope with the negative consequences of online content risks in communicative or proactive ways plays a large role in the degree of harm they experience after being exposed to these contents (Vandoninck et al., 2013). In line with these earlier findings, the current study found that the association between online content risk experiences and lower levels of wellbeing significantly weakens when youths are more resilient. Hence, the wellbeing of youths who seek social support or take action to cope after they have been exposed to risky contents seems to be determined less by exposure to these risks.

Previous studies have shown that most children and youths are quite resilient to feelings of harm after an online risk experience (Livingstone et al., 2011). Is it a problem, then, that youths are exposed to risky online content if they are resilient to its potentially harmful outcomes? Risk exposure certainly is not always problematic and parents and other caretakers should not overly shield their children from these risks, as they are necessary for children and youths to develop online resilience in the first place (Coleman \& Hagell, 2007; Livingstone et al., 2011). Through this risk exposure, youths acquire the coping strategies that aid them in effectively eliminating feelings of harm that emerge from it. This is central to the empowerment approach in which this study places itself: Youths should have their own agency over their Internet use and should develop the necessary skills to deal with potential negative consequences of this Internet use. However, parents should remain alert about exposure to online risky content when their child is less resilient to feelings of harm that result from these risks, as the wellbeing of this group of young users will be affected by it the most. By being present when the child is exploring the online world, parents allow their children to be exposed to these risks and hence to gain resilience, but still have the possibility to intervene and provide support when the child is not able to cope with the risks encountered by itself.

Despite its contributions to the literature and its implications for practice, the current study has four limitations. First, cross-sectional data were analyzed, so the current study does not provide evidence to make causal conclusions about the associations that were found. We encourage future research to investigate the associa- 
tions between online opportunities, risks, and resilience over a longer period of time. Second, the self-report nature of the data might cause biases. For example, some youths might feel uncomfortable or ashamed about their online risk experiences and might hence not report the truth. Wellbeing is a sensitive subject where youths might inflate their reports of their wellbeing to hide how they truly feel. Third, the scope of this study was only limited to online content risks. Hence, insights about contact and conduct risks are not included in this study. Further research could broaden the scope and focus on each type of these risks. Fourth, the current study did not directly distinguish between different types of opportunities. Furthermore, it did not distinguish between communicative coping and proactive coping as different forms of online resilience: While communicative coping strategies are often employed to deal with negative consequences of online risk experiences, proactive coping is often aimed at preventing further feelings of harm as a result of negative online experiences in the future. Further research could nuance the current findings by exploring the associations between different types of opportunities and their value for youths' online risk experiences and overall wellbeing; as well as the different contributions of communicative and proactive coping strategies on youths' wellbeing.

\section{Conclusion}

The goal of the current study was twofold. First, it aimed to investigate the associations between online opportunities, online content risk experiences, and youths' wellbeing. Second, it wanted to examine whether online resilience, or the ability to effectively cope with negative experiences, served as a safeguard of youths' wellbeing from the potential negative consequences of exposure to risky online content. These questions were studied using data collected within the EU Kids Online project from 1436 youths in Flanders. This study corroborates earlier findings that the more online opportunities youths take up online, the more they encounter risks. While taking up different opportunities proved beneficial to youths' wellbeing, online content risks proved harmful. Online resilience emerged as a significant moderator. Hence, youths who are more resilient experience less harm to their wellbeing as a result of exposure to risky online content than youths who are less resilient. Based on these findings, we advise parents, educators, and other caretakers to encourage their child's development of online resilience through the creation of a safe environment for the use of communicative and proactive coping strategies.

\section{Acknowledgments}

This work is part of the EU Kids Online project. More information the project and the full comparative report can be found on www.eukidsonline.net. This publication was made possible through funding support of the KULeuven Fund for Fair Open Access.

\section{Conflict of Interests}

The author declares no conflict of interests.

\section{Supplementary Material}

Supplementary material for this article is available online in the format provided by the author (unedited).

\section{References}

Apestaartjaren. (2018). De digitale leefwereld van kinderen en jongeren [The digital enviornment of children and youths]. Ghent: Mediawijs.

Bandalos, D. L. (2014). Relative performance of categorical diagonally weighted least squares and robust maximum likelihood estimation. Structural Equation Modeling: A Multidisciplinary Journal, 21(1), 102-116.

Baumrind, D. (1991). Effective parenting during the early adolescence transition. In P. A. Cowan \& M. E. Hetherington (Eds.), Advances in family research (pp. 111-163). Hillsdale: Erlbaum.

Bollen, K. A., \& Stine, R. A. (1992). Bootstrapping goodness-of-fit measures in structural equation models. Sociological Methods \& Research, 21(2), 205-229.

Coleman, J., \& Hagell, A. (2007). Adolescence, risk and resilience: Against the odds. West Sussex: John Wiley.

d'Haenens, L., Vandoninck, S., \& Donoso, V. (2013). How to cope and build online resilience? London: EU Kids Online.

El Asam, A., \& Katz, A. (2018). Vulnerable young people and their experience of online risks. HumanComputer Interaction, 33(4), 281-304.

Enders, C. K. (2002). Applying the Bollen-Stine bootstrap for goodness: Of-fit measures to structural equation models with missing data. Multivariate Behavioral Research, 37(3), 359-377.

Fry, K. (2015). Developing media literacy: Managing fear and moving beyond. Journal of Media Literacy Education, 6(3), 65-70.

Giddens, A. (1991). Modernity and self-identity. Stanford, CA: Stanford University Press.

Görzig, A. (2016). Adolescents' experience of offline and online risks: Separate and joint propensities. Computers in Human Behavior, 56, 9-13.

Hasebrink, U., Livingstone, S., \& Haddon, L. (2009). Comparing children's online opportunities and risks across Europe: Cross-national comparisons for EU Kids Online. London: EU Kids Online.

Hinduja, S., \& Patchin, J. W. (2017). Cultivating youth resilience to prevent bullying and cyberbullying victimization. Child Abuse \& Neglect, 73, 51-62.

Ito, M., Baumer, S., Bittanti, M., Boyd, D., Cody, R., Herr- 
Stephenson, B., . . . Tripp, L. (2010). Hanging out, messing around, and geeking out: Kids living and learning with new media. Cambridge, MA: The MIT Press.

Ito, M., Horst, H., Bittanti, M., Boyd, D., Herr-Stephenson, B., Lange, P. G., . . . Robinson, L. (2008). Living and learning with new media: Summary of findings from the digital youth project. Chicago, IL: The John D. and Catherine T. MacArthur Foundation.

Keipi, T., Oksanen, A., Hawdon, J., Näsi, M., \& Räsänen, P. (2017). Harm-advocating online content and subjective well-being: A cross-national study of new risks faced by youth. Journal of Risk Research, 20(5), 634-649.

Keipi, T., Räsänen, P., Oksanen, A., Hawdon, J., \& Näsi, M. (2018). Exposure to online hate material and subjective well-being: A comparative study of American and Finnish youth. Online Information Review, 42(1), 2-15.

Kellner, D., \& Share, J. (2007). Critical media literacy is not an option. Learning Inquiry, 1, 59-69.

Kline, R. B. (2011). Principles and practice of structural equation modelling. New York, NY: Guilford Press.

Lazarus, R. S. (2006). Emotions and interpersonal relationships: Toward a person-centered conceptualization of emotions and coping. Journal of Personality, 74(1), 9-46.

Livingstone, S. (2008). Taking risky opportunities in youthful content creation: Teenagers' use of social networking sites for intimacy, privacy and selfexpression. New Media \& Society, 10(3), 393-411.

Livingstone, S. (2016). Reframing media effects in terms of children's rights in the digital age. Journal of Children and Media, 10(1), 4-12.

Livingstone, S., Haddon, L., Görzig, A., \& Ólafsson, K. (2011). Risks and safety on the internet: The perspective of European children-Full findings and policy implications from the EU Kids Online survey of 9-16 year olds and their parents in 25 countries. London: EU Kids Online.

Livingstone, S., \& Helsper, E. (2010). Balancing opportunities and risks in teenagers' use of the internet: The role of online skills and internet self-efficacy. New Media and Society, 12(2), 309-329.

Livingstone, S., Mascheroni, G., \& Staksrud, E. (2015). Developing a framework for researching children's online risks and opportunities in Europe. London: EU Kids Online.

Livingstone, S., Mascheroni, G., \& Staksrud, E. (2018). European research on children's internet use: Assessing the past and anticipating the future. New Media and Society, 20(3), 1103-1122.

Livingstone, S., Ólafsson, K., Helsper, E. J., LupiáñezVillanueva, F., Veltri, G. A., \& Folkvord, F. (2017). Maximizing opportunities and minimizing risks for children online: The role of digital skills in emerging strategies of parental mediation. Journal of Communication, 67(1), 82-105.
Lwin, M. O., Li, B., \& Ang, R. P. (2012). Stop bugging me: An examination of adolescents' protection behavior against online harassment. Journal of Adolescence, 35(1), 31-41.

Machmutow, K., Perren, S., Sticca, F., \& Alsaker, F. D. (2012). Peer victimisation and depressive symptoms: Can specific coping strategies buffer the negative impact of cybervictimisation? Emotional and Behavioural Difficulties, 17(3/4), 403-420.

Masten, A. S., \& Gewirtz, A. H. (2006). Vulnerability and resilience in early child development. In K. McCartney \& D. Philips (Eds.), Blackwell handbook of early childhood development (pp. 22-43). Malden, MA: Blackwell.

McHugh, B. C., Wisniewski, P., Rosson, M. B., \& Carroll, J. M. (2018). When social media traumatizes teens: The roles of online risk exposure, coping, and post-traumatic stress. Internet Research, 28(5), 1169-1188.

O’Neill, B., Staksrud, E., \& Mclaughlin, S. (2013). Towards a better internet for children. Gothenburg: Nordicom.

Pabian, S., \& Vandebosch, H. (2016). An investigation of short-term longitudinal associations between social anxiety and victimization and perpetration of traditional bullying and cyberbullying. Journal of Youth and Adolescence, 45(2), 328-339.

Rosseel, Y. (2012). Lavaan: An R package for structural equation modelling. Journal of Statistical Software, 48(2), 1-36.

Seiffge-Krenke, I., \& Klessinger, N. (2000). Long-term effects of avoidant coping on adolescents' depressive symptoms. Journal of Youth and Adolescence, 29(6), 617-630.

Smahel, D., Machackova, H., Mascheroni, G., Dedkova, L., Staksrud, E., Ólafsson, K., . . . Hasebrink, U. (2020). EU Kids Online 2020: Survey results from 19 countries. London: London School of Economics and Political Science.

Smahel, D., \& Wright, M. F. (2014). The meaning of online problematic situations for children: Results of qualitative cross-cultural investigation in nine European countries. London: EU Kids Online.

Staksrud, E., \& Livingstone, S. (2009). Children and online risk: Powerless victims or resourceful participants? Information, Communication \& Society, 12(3), 364-387.

Strasburger, V. C., Wilson, B. J., \& Jordan, A. B. (2014). Children, adolescents, and the media (3rd ed.). Thousand Oaks, CA: Sage.

Valkenburg, P. M., \& Peter, J. (2011). Online communication among adolescents: An integrated model of its attraction, opportunities, and risks. Journal of Adolescent Health, 48(2), 121-127.

Vandoninck, S. (2016). Dealing with online risks: How to develop adequate coping strategies and preventive measures with a focus on vulnerable children (Unpublished Doctoral dissertation). KU Leuven, Leuven, Belgium. 
Vandoninck, S., \& d'Haenens, L. (2015). Children's online coping strategies: Rethinking coping typologies in a risk-specific approach. Journal of Adolescence, 45, 225-236.

Vandoninck, S., d'Haenens, L., \& Ichau, E. (2014). Net children go mobile: Rapport België. [Net children go mobile: Report Belgium]. Brussels: Cultuur, Jeugd, Sport, Media.

Vandoninck, S., d'Haenens, L., \& Roe, K. (2013). Online risks: Coping strategies of less resilient children and teenagers across Europe. Journal of Children and Media, 7(1), 60-78.

Vandoninck, S., d'Haenens, L., \& Segers, K. (2012). Coping and resilience: Children's responses to online risks. In
S. Livingstone, L. Haddon, \& A. Görzig (Eds.), Children, risk and safety on the internet (pp. 205-218). Bristol: The Policy Press.

van Nieuwenhuijzen, M., Junger, M., Klein Velderman, M., Wiefferink, K. H., Paulussen, T. W. G. M., Hox, J., \& Reijneveld, S. A. (2009). Clustering of healthcompromising behavior and delinquency in adolescents and adults in the Dutch population. Preventive Medicine, 48(6), 572-578.

Vissenberg, J., \& d'Haenens, L. (2020). Online risks, harm, and resilience: Flemish findings from the $2020 \mathrm{EU}$ Kids Online survey. Leuven: EU Kids Online. Retrieved from https://bit.ly/2K9aLNY

\section{About the Authors}
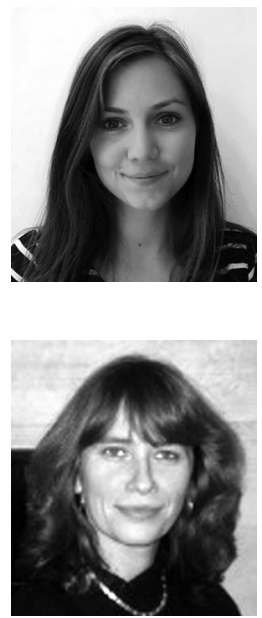

Joyce Vissenberg is a PhD Student at the Institute for Media Studies. Her research focuses on media and digital literacy, especially in children and youth. In her PhD, where she particularly investigates youths' news literacy, she studies their credibility assessment strategies of online news. Other research interests include the role of online resilience in fostering youth wellbeing.

Leen d'Haenens is Full Professor at the Faculty of Social Sciences, KU Leuven, where she teaches 'Analysis of Media Texts' and 'European Media Policy' at BA level, and 'Media, Audiences and Identity' at MA level. Her current research is on media representations of Islam and migration and the triggers for ideological polarization and radicalization in mainstream and social media. She also conducts research on (social) media use by children and young people in relation to their wellbeing, with a focus on vulnerabilities and young people with a migration background. 